\title{
von Recklinghausen oscillotonometer
}

TW Wong, FHKAM (Emergency Medicine)

Member of the Education and Research Committee, Hong Kong Museum of Medical Sciences Society

https://doi.org/10.12809/hkmj-hkmms202010

Stephen Hales is known as the first person to directly measure the blood pressure in a horse, in the 18th century. It was not until the next century when the sphygmograph was invented to record the blood pressure indirectly. ${ }^{1}$ Blood pressure was determined by noting the weight required to obliterate the radial pulse. In the $1880 \mathrm{~s}$, von Basch introduced his sphygmomanometer, which recorded the pressure need to obliterate the radial pulse using a device similar to the aneroid barometer. In 1897, Hill and Barnard reported in the British Medical Journal their version of sphygmomanometer using an arm cuff and a tambour as pressure gauge. ${ }^{2}$ Riva-Rocci in Italy also introduced a rubber arm cuff in 1896 to occlude the brachial artery and he used a mercury manometer to measure the pressure. Riva-Rocci's mercury sphygmomanometer was introduced in the United States by Harvey Cushing, a renowned neurosurgeon. It became popular in the early 20th century when the introduction of the Korotkov sounds in 1905 made measuring of both systolic and diastolic pressure more accurate. ${ }^{3}$ In contrast, the oscillotonometer was more widely used in continental Europe.

Heinrich von Recklinghausen (1867-1942) popularised his oscillotonometer in the 1930s. $\mathrm{He}$ was a German physician and scientist from Wurzburg and his main contribution was on the physiology of blood pressure measurement.
His father was the renowned pathologist who described von Recklinghausen's neurofibromatosis. There were two models of the von Recklinghausen oscillotonometer, the Scala Alternans and the later Scala Alternans Altera. The one possessed by the Hong Kong Museum of Medical Sciences was donated by Ruttonjee Hospital and it belonged to the later model.

The von Recklinghausen oscillotonometer has two overlapping cuffs, measuring $5 \mathrm{~cm}$ and $10 \mathrm{~cm}$ respectively and can be inflated by a single inflation bulb. ${ }^{4}$ Both cuffs are connected by rubber tubing to a dial mounted in a hermetically sealed metal case. The case contains two tambours, one connected to the upper cuff and open to atmosphere and the other to the lower sensing cuff and amplifies arterial pulsation. The dial needle is connected indirectly to the tambours and a thumb screw is used to adjust the dial needle to zero (Fig). When taking a blood pressure reading, both cuffs are inflated to above the presumed systolic pressure using the inflation bulb. Deflation via the release valve is activated by the sustained leak lever. As the pressure drops slowly, pulsation of the partially occluded artery under the lower cuff will cause the needle in the case to oscillate. At the point where one observes a definite increase in the oscillation, the lever is released and the pointer will stop and indicate the systolic pressure on the dial. Further deflation by activation of the lever will

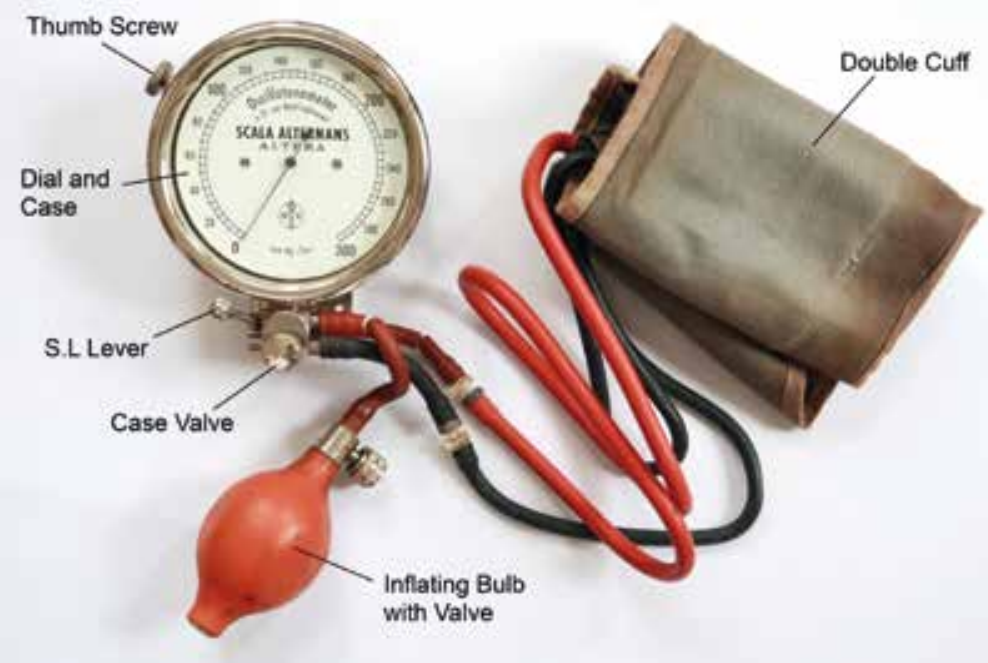

FIG. Components of the von Recklinghausen oscillotonometer 
allow a reading of the diastolic pressure when there is a definite decrease in the oscillations. ${ }^{5}$

One of the advantages of the oscillotonometer over the mercury sphygmomanometer is that auscultation with a stethoscope is unnecessary. The technique however can be inaccurate in a patient with an irregular pulse, for example due to atrial fibrillation, as it relies heavily on a constant pulse volume. The von Recklinghausen oscillotonometer was not as popular as the mercury sphygmomanometer in Hong Kong, unlike in Europe. However, both were gradually replaced by new automatic digital sphygmomanometers, which use electronic sensors to detect pulsations transmitted from the artery. The United Nations Minamata Convention on Mercury, which was adopted to protect human health and the environment from the adverse effects of mercury, will come into effect in 2020. This will spell the end of the mercury sphygmomanometer in countries which have ratified the Convention. Public hospitals in Hong Kong have already phased out the traditional mercury sphygmomanometer.

\section{References}

1. Lau CP. The sphygmograph. Hong Kong Med J 2016;22:402-3.

2. Lawrence C. Physiological apparatus in the Wellcome museum. 3. Early sphygmomanometers. Med Hist 1979;23:4748.

3. Crenner CW. Introduction of the blood pressure cuff into U.S. medical practice: technology and skilled practice. Ann Intern Med 1998;128:488-93.

4. Ball C, Westhorpe RN. Blood pressure monitoring-the von Recklinghausen oscillotonometer. Anaesth Intensive Care 2009;37:161.

5. Corall IM, Strunin L. Assessment of the von Recklinghausen oscillotonometer. Anaesthesia 1975;30:59-66. 